\title{
Elevation of Bombina variegata peptide 8 in mice with
} collagen-induced arthritis

\author{
Daitaro Kurosaka*1,2, Kentaro Noda ${ }^{1}$, Ken Yoshida1 ${ }^{1}$, Kazuhiro Furuya1, \\ Taro Ukichi ${ }^{1}$, Eigo Takahashi ${ }^{1}$, Maimi Yanagimachi ${ }^{1}$, Isamu Kingetsu ${ }^{1}$, \\ Saburo Saito ${ }^{2}$ and Akio Yamada ${ }^{1}$
}

\author{
Address: ${ }^{1}$ Division of Rheumatology, Department of Internal Medicine, Jikei University School of Medicine, Tokyo, Japan and ${ }^{2}$ Department of \\ Molecular Immunology, Institute of DNA Medicine, Jikei University School of Medicine, Tokyo, Japan \\ Email: Daitaro Kurosaka* -d_kurosaka@jikei.ac.jp; Kentaro Noda - knoda3353@jikei.ac.jp; Ken Yoshida - k.yoshida@jikei.ac.jp; \\ Kazuhiro Furuya -frykzhr@jikei.ac.jp; Taro Ukichi - ukichi@jikei.ac.jp; Eigo Takahashi - t-815@jikei.ac.jp; \\ Maimi Yanagimachi - maimy@jikei.ac.jp; Isamu Kingetsu - i_king@jikei.ac.jp; Saburo Saito - misaburo@jikei.ac.jp; \\ Akio Yamada - yamada@jikei.ac.jp \\ * Corresponding author
}

Published: 30 April 2009

BMC Musculoskeletal Disorders 2009, 10:45 doi:10.1 I86/147|-2474-10-45

This article is available from: http://www.biomedcentral.com/I47/-2474//0/45

(C) 2009 Kurosaka et al; licensee BioMed Central Ltd.

This is an Open Access article distributed under the terms of the Creative Commons Attribution License (http://creativecommons.org/licenses/by/2.0), which permits unrestricted use, distribution, and reproduction in any medium, provided the original work is properly cited.

\begin{abstract}
Background: Bombina variegate peptide 8 (Bv8) is a small protein secreted by frog skin. Recently it has been shown to contribute to tumor angiogenesis in mouse model. The purpose of this study was to investigate Bv8 in mice with type II collagen-induced arthritis (CIA).

Methods: We induced CIA in male DBA/IJ mice. The severity of arthritis was evaluated based on an arthritis score. RNA was extracted from the joint, and examined for Bv8 mRNA expression by RT-PCR and real-time RT-PCR. Synovial tissue and bone marrow were immunohistochemically examined using anti-Bv8 antibody.

Results: The level of Bv8 mRNA expression in the joint was below the detection limit in the control group, but was elevated in the CIA group, and was correlated with the arthritis score. In addition, an increase in Bv8-positive cells was observed in the synovium and bone marrow in the CIA group.
\end{abstract}

Conclusion: $\mathrm{Bv} 8$ was elevated in the synovium and bone marrow of $\mathrm{ClA}$ mice, suggesting that $\mathrm{Bv} 8$ plays an important role in the pathogenesis of arthritis.

\section{Background}

Bombina variegata peptide 8 (Bv8)/prokineticin-2 is a protein isolated from skin secretions of the frog Bombina variegata $[1,2]$. Endocrine gland-derived VEGF, also known as prokineticin-1, belongs to the same family as $\mathrm{Bv} 8$ [3]. Bv8 has diverse functions, being involved in angiogenesis, gastrointestinal motility, neurogenesis, circadian rhythm regulation, hormone release, and the pain threshold [4,5].
Recently, Ferrara et al. reported an interesting study on angiogenesis: tumor-derived granulocyte colony-stimulating factor (G-CSF) mobilized bone marrow Bv8-positive cells to tumor sites, and these cells were CD11b+/Gr1+, promoting tumor angiogenesis via the mediation of Bv8[6]. On the other hand, angiogenesis is closely involved in the pathogenesis of type II collagen-induced arthritis (CIA), a model of rheumatoid arthritis $[7,8]$. In 
addition, an increase in CD11b+/Gr1+ cells was reported in the joints of CIA mice $[9,10]$. These observations suggest that Bv8 is involved in the pathogenesis of arthritis in CIA mice. Therefore, in this study, we investigated Bv8 in CIA mice.

\section{Methods}

\section{Induction of arthritis in mice}

All animal experiments were performed according to the Guidelines on Animal Experimentation of the Jikei University School of Medicine. Five-week-old male DBA/1J mice were purchased from Kyudo Ltd. (Fukuoka, Japan), and used after an acclimatization period of 1 week together as a group. Collagen-induced arthritis was induced as follows.[8] A $0.3 \%$ solution of bovine type II collagen(Cosmo Bio Co., Ltd., Tokyo, Japan) was emulsified in an equal volume of complete Freund's adjuvant (Difco Laboratories, Detroit, MI, USA). One hundred microlitres of this emulsion was injected intradermally into the dorsal root of the tail of 6 -week-old male DBA/1J mice. This day was defined as day 0 . Before arthritis onset, the mice received a booster injection of $0.3 \%$ bovine type II collagen solution emulsified in incomplete Freund's adjuvant on day 21, as described above for the primary injection. We used non-immunized mice as a control. Each experimental group consisted of five mice. mRNA analysis was performed twice, and the reproducibility was confirmed.

\section{Macroscopic evaluation of arthritis}

The severity of arthritis was evaluated by the sum of the score for each wrist and ankle joint based on the following arthritis scale: 0 , normal; 1 , swelling of digits alone or mild swelling of wrist and ankle joints; 2, clear swelling of wrist and ankle joints; and 3, ankylosis or deformity of wrist and ankle joints.

\section{RNA extraction from joints}

Mice were sacrificed under diethyl ether inhalation anesthesia on days 21,24, 28, and 35 after the first immunization, and the fore- and hindlimbs were amputated 5 $\mathrm{mm}$ proximal to the wrist and ankle joints, respectively.

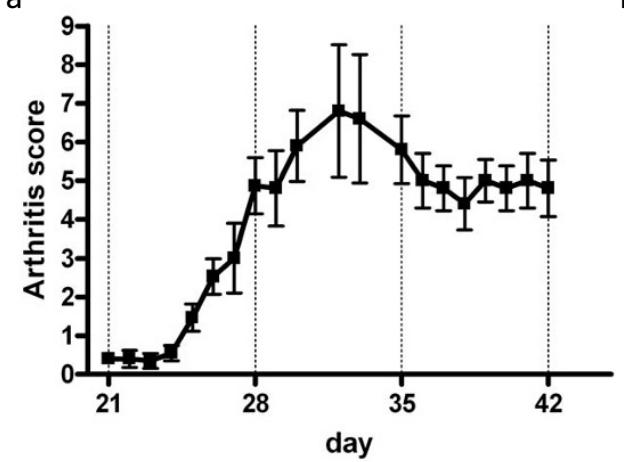

C

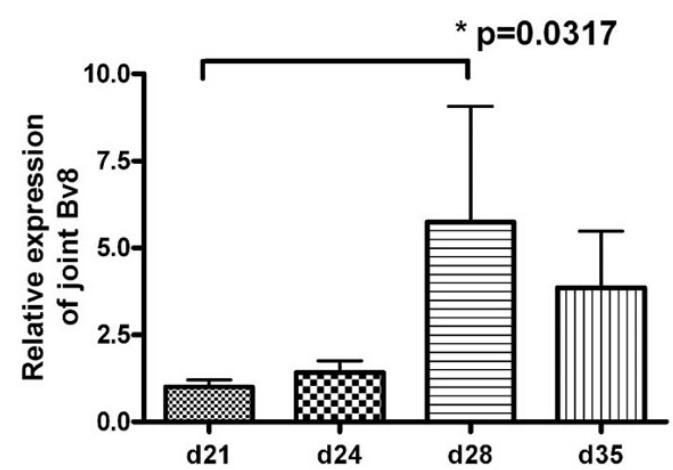

b

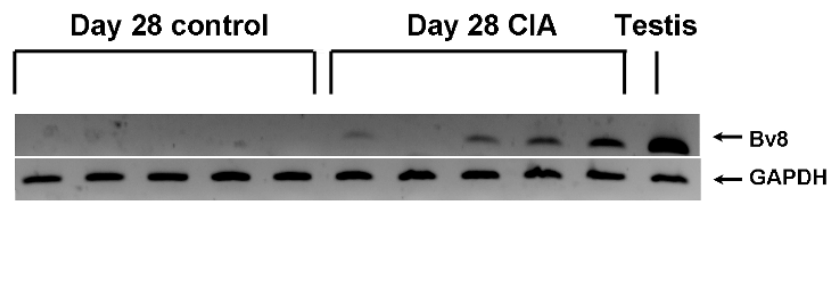

d

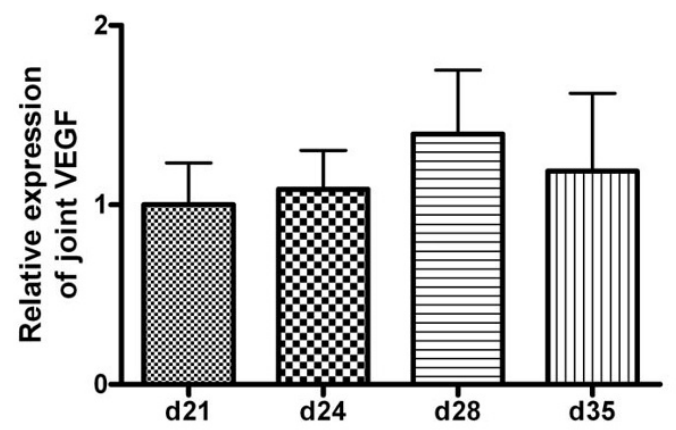

Figure I

Correlation between the arthritis score and Bv8 mRNA expression. One group consisted of 5 mice. $b$ shows the results of analysis by RT-PCR. $c$ and $d$ show the results of analysis by real-time PCR. The relative expression of Bv8 and VEGF mRNA was standardized to that of GAPDH mRNA. The results are expressed relative to day $21 \mathrm{CIA}$ mice, arbitrarily assigned a value of I.0. a. Changes in the arthritis score. b. Comparison of Bv8 mRNA expression in joint tissue on day 28 between the $\mathrm{CIA}$ and control groups. c. Bv8 mRNA expression in arthritic joints on days $2 \mathrm{I}, 24,28$, and 35. d. VEGF mRNA expression in arthritic joints on days $21,24,28$, and 35 . 
RNA was extracted using ISOGEN (Nippon Gene Co., Ltd., Tokyo, Japan).

\section{RT-PCR}

cDNA was synthesized using SuperScript ${ }^{\mathrm{TM}}$ II Reverse Transcriptase (Invitrogen, Tokyo, Japan). PCR was performed employing Gene Amp PCR System 9700 (Applied Biosystems, Foster City, CA, USA) using Ampli Taq Gold (Applied Biosystems, Foster City, CA, USA). Testis-derived RNA was used as a control. The primers used for Bv8 and GAPDH were as follows: Bv8, 5'-AGAGGAAGAAGGAGGTTC-3' and 5'-GAGTAAGGGTGTGTCTGTCT-3'; and GAPDH, 5'-TCACCATCTTCCAGGAGCG-3' and 5'CTGCTTCACCACCTTCTTGA-3'.

\section{Real-time RT-PCR}

cDNA was synthesized using a QuantiTect Reverse Transcription Kit (Qiagen K.K., Tokyo, Japan). Real-time PCR was performed in an ABI PRISM Sequence Detection System (Applied Biosystems, Foster City, CA, USA) using a QuantiTect SYBR Green PCR Kit (Qiagen K.K., Tokyo, Japan) and Quantitect Primer Assay (Mm Prok2 1 SG Quantitect Primer Assay, Mm Gapd 1 SG Quantitect
Primer Assay and Mm vegfa 1 SG Quantitect Primer Assay; Qiagen K.K., Tokyo, Japan). The results were analyzed using the $\Delta \Delta \mathrm{Ct}$ method.

\section{Histological evaluation}

On day 28 , mice were anesthetized by an intraperitoneal injection of pentobarbital, followed by perfusion fixation with $4 \%$ paraformaldehyde. Subsequently, the fore- and hindlimbs were amputated $5 \mathrm{~mm}$ proximal to the wrist and ankle joints, respectively, and were immersion-fixed in $4 \%$ paraformaldehyde at $4^{\circ} \mathrm{C}$ for 2 days. The fixed limbs were delipidated with $100 \%$ ethanol at $4^{\circ} \mathrm{C}$ for 1 day, and then decalcified with EDTA at room temperature for 3 days. Thin sections were stained with $\mathrm{H}$ and $\mathrm{E}$, and immunostained with anti-prokineticin 2 and anti Gr-1 antibodies. Thin paraffin sections were deparaffinized with xylene, and the xylene was removed with $100 \%$ ethanol. To activate the antigen, sections were incubated in 1 $\mathrm{mM}$ sodium citrate buffer at $98^{\circ} \mathrm{C}$ for $2 \mathrm{~h}$. Endogenous peroxidase in sections was inactivated with a peroxidaseblocking reagent (Dako Cytomation Co., Ltd., Kyoto, Japan). The sections were washed with PBS, blocked with $10 \%$ normal rabbit serum, and incubated with the pri-
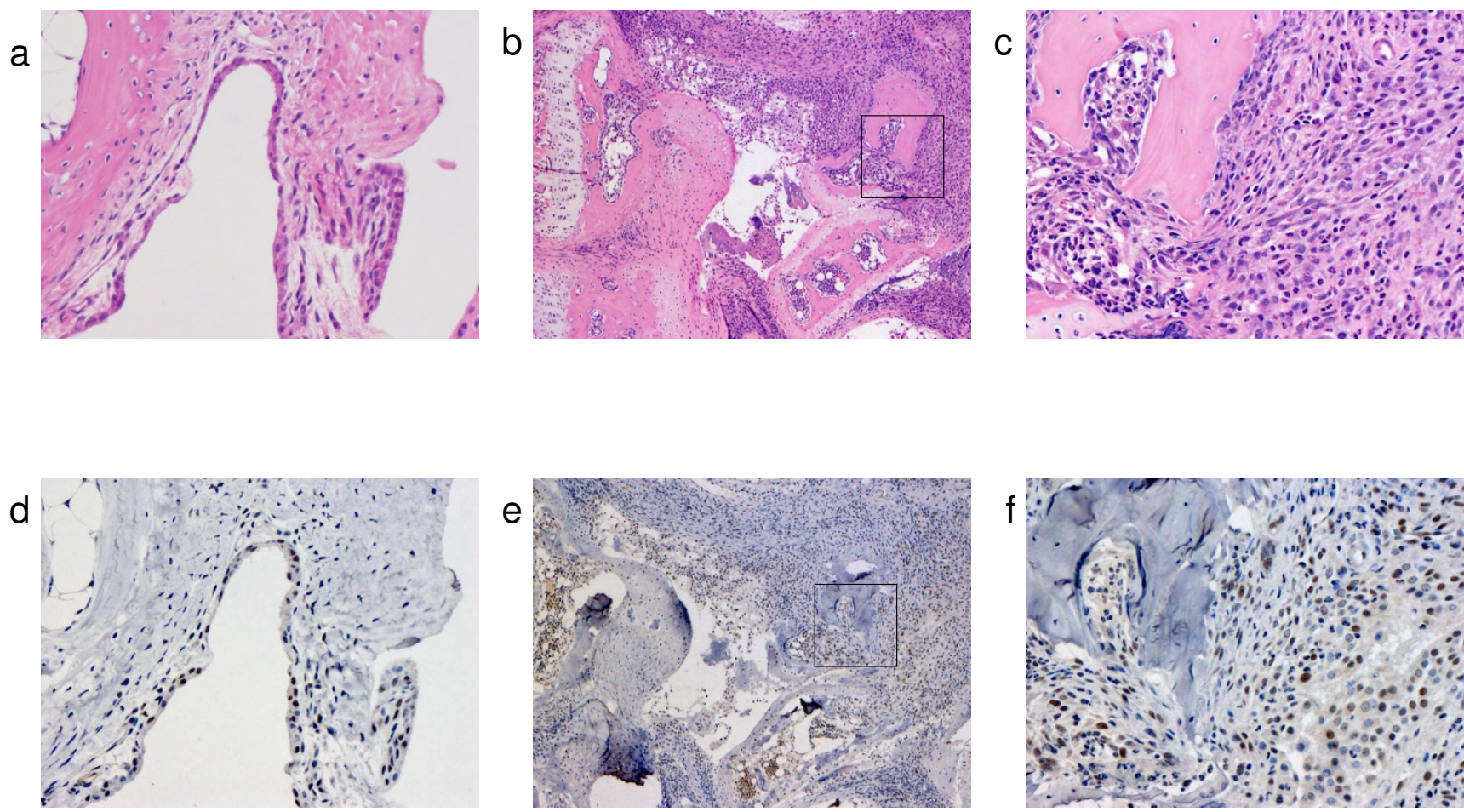

\section{Figure 2}

Histopathological examination of the synovium. Bv8 in Figs. $d$, e, and $f$ was stained brown. a. HE-staining of the synovium in the control group $(\times 200)$. b. HE-staining of the synovium in the CIA group $(\times 50)$. c. HE-staining of the synovium in the CIA group $(\times 200)$. The area in the box in Fig. b is enlarged. $d$. Immunohistochemical staining of the synovium with anti-Bv8 antibody in the control group $(\times 200)$. e. Immunohistochemical staining of the synovium with anti-Bv8 antibody in the CIA group ( $\times 50)$. f. Immunohistochemical staining of the synovium with anti-Bv8 antibody in the CIA group $(\times 200)$. The area in the box in Fig. e is enlarged. 

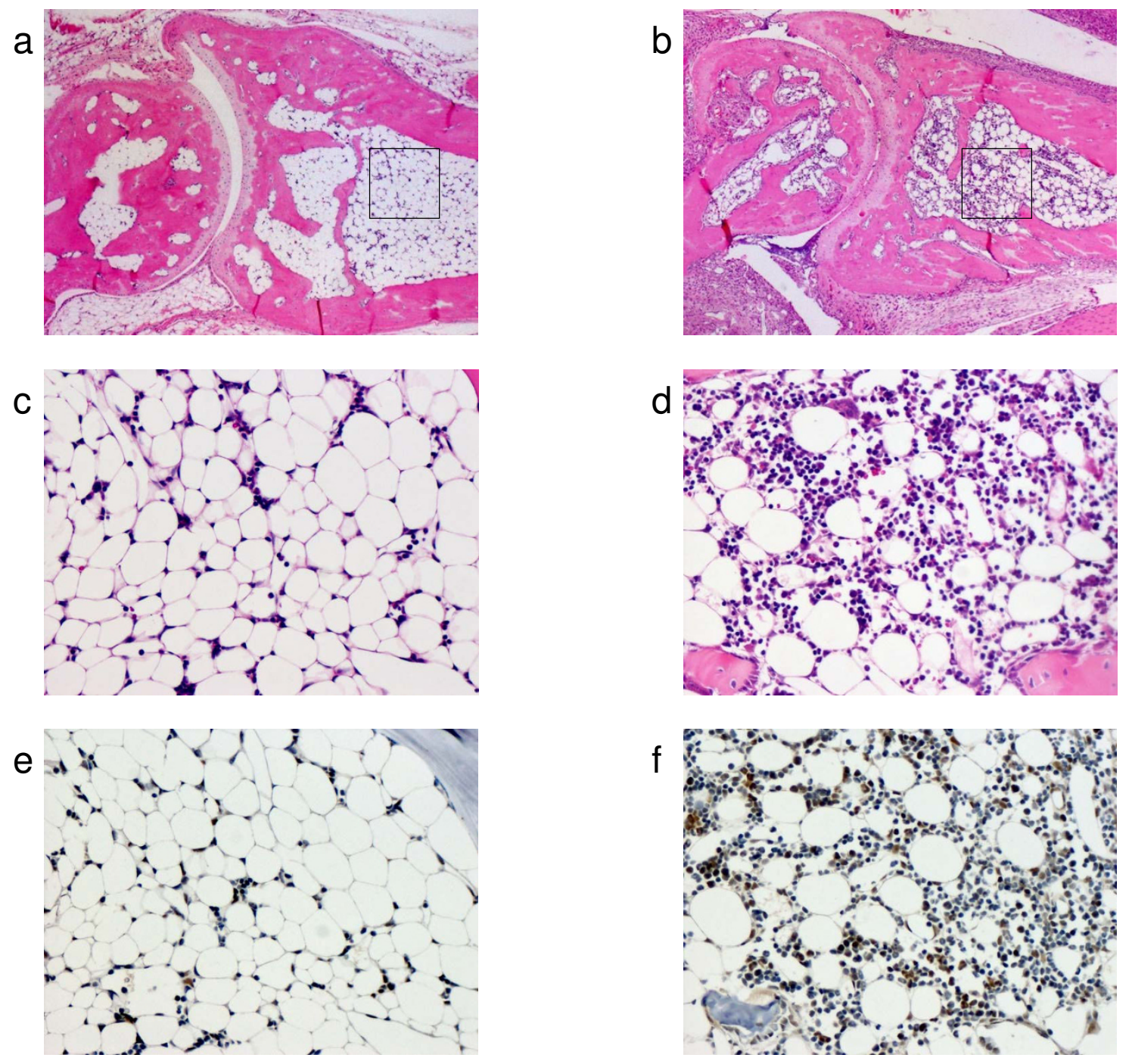

\section{Figure 3}

Histopathological examination of bone marrow in the distal tibia. In Figs. e and f, Bv8 was stained brown. a. HE-staining of bone marrow in the control group $(\times 50)$. b. HE-staining of bone marrow in the ClA group $(\times 50)$. c. HE-staining of bone marrow in the control group $(\times 200)$. The area in the box in Fig. a is enlarged. d. HE-staining of bone marrow in the CIA group $(\times 200)$. The area in the box in Fig. $b$ is enlarged. e. Immunohistochemical staining of bone marrow with anti-Bv8 antibody in the control group $(\times 200)$. f. Immunohistochemical staining of bone marrow with anti-Bv8 antibody in the CIA group $(\times 200)$.

mary antibody, a 1:200 dilution of goat anti-mouse prokineticin 2 antibody (Santa Cruz Biotechnology, Inc., Santa Cruz, CA, USA), at $4^{\circ} \mathrm{C}$ overnight, and washed with PBS. Subsequently, the sections were reacted with Simple Stain MAX-PO(G) (Nichirei Bioscience Inc., Tokyo, Japan) as the secondary antibody at room temperature for $30 \mathrm{~min}$, and washed with PBS. The color was developed by the addition of Simple Stain DAB Solution (Nichirei Bioscience Inc., Tokyo, Japan) for $10 \mathrm{~min}$ at room temperature. The sections were finally counterstained with hematoxylin. For Gr-1 staining, the sections were incubated with primary antibody, a 1:100 dulution of rat anti- mouse Gr-1 antibody (Becton, Dickinson and Co., Tokyo, Japan), at $4{ }^{\circ} \mathrm{C}$ overnight, and reacted with biotin-conjugated rabbit anti-rat IgG antibody (Dako Cytomation Co., Ltd., Kyoto, Japan) and ALP-labeled streptavidin (Nichirei Bioscience Inc., Tokyo, Japan). The color was developed by the addition of Vector Blue(Vector Laboratories, Inc., CA, USA)for $45 \mathrm{~min}$ at room temperature.

\section{Statistical analysis}

Data obtained by real-time PCR were analyzed using the Mann-Whitney U-test. A p-value of less than 0.05 was considered significant. 


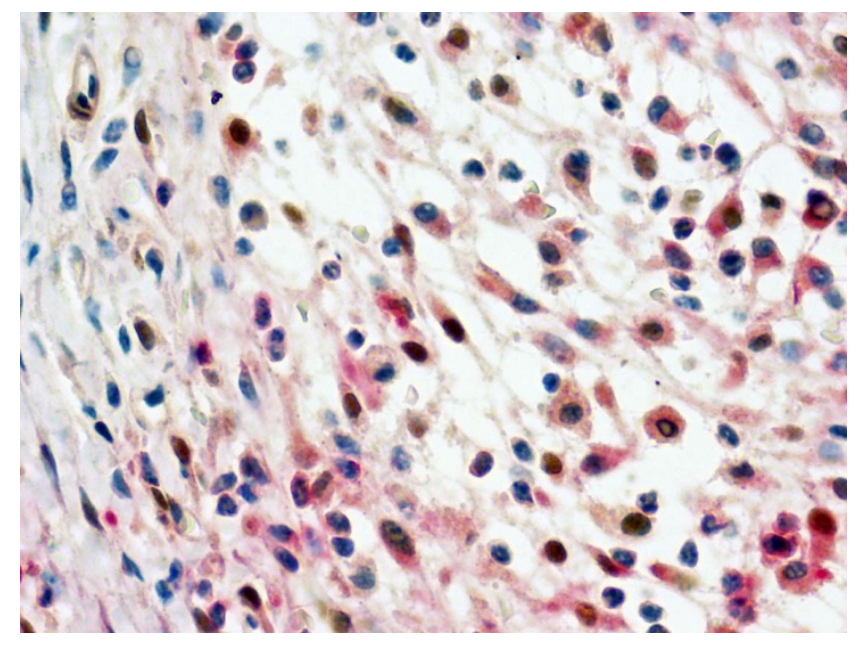

Figure 4

Immunohistochemical staining of the synovium with anti-Bv8 and anti-Gr-I antibodies in the CIA group $(\times 400)$. Bv8 and Gr-I were stained brown and red, respectively.

\section{Results}

Mice developed CIA 2-3 days after the booster injection (on day 21). The severity of arthritis peaked on approximately day 30 (Fig. 1a). RNA was extracted from the joint on days $21,24,28$, and 35 , and was analyzed for Bv8 mRNA expression. On day 28, Bv8 mRNA expression was detectable by RT-PCR in 4 of the 5 CIA mice, but was below the detection limit in all control mice (Fig. 1b). Similar results were obtained in the CIA and control mice sacrificed on day 35 (data not shown). It is of note that Bv8 mRNA expression could not be detected in the RNA of CIA mice with minimal arthritis. Next, changes in Bv8 mRNA expression were analyzed by real-time RT-PCR (Fig. 1c). The level of Bv8 expression increased rapidly from day 28 , and tended to decrease gradually thereafter. The time course of Bv8 mRNA expression roughly paralleled the arthritis score. Mann-Whitney U-test analysis showed significant differences in the Bv8 mRNA expression level between the mice sacrificed on days 21 and 28 . The expression of mRNA for VEGF, an angiogenesis-promoting factor, was similarly analyzed. The level of VEGF expression was slightly higher on days 28 and 35 than on day 21 (Fig. 1d). The relative VEGF mRNA expression level was 1.39 , as compared to 5.75 for Bv8, indicating that the rate of increase in Bv8 was higher than that in VEGF in arthritis. Next, to analyze Bv8 expression at the protein level, we examined synovial tissue and bone marrow immunohistochemically using anti-Bv8 antibody(Figs. 2, 3). Bv8-positive cells were observed in the superficial layer of the normal synovium (Fig. 2d), but were clearly increased in the arthritic pannus (Fig. 2e, f). Morphologically, most Bv8-positive cells were macrophage-like, although some of them could not be clearly identified. In addition, Bv8-positive cells were observed in the normal bone marrow of the distal tibia as well(Fig. 3e), but were markedly increased in the bone marrow of CIA mice(Fig. 3f). Morphologically, Bv8-positive cells were predominantly myeloid-lineage cells(Fig. 3c, d). To characterize Bv8-positive cells in more detail, arthritic joints were double-stained with anti-Bv8 and anti-Gr-1 antibodies. Most Bv8-positive cells observed in arthritic synovia were also positive for Gr-1 (Fig. 4).

\section{Discussion}

The development of arthritis was associated with elevated Bv8 mRNA expression in the arthritic joint of CIA mice. Histopathologically, Bv8-positive cells were increased in the synovium and bone marrow. These results suggest that Bv8 is involved in the pathogenesis of arthritis. Further, the time course of changes in the expression of mRNA for VEGF, a potent angiogenesis-promoting factor, paralleled that in the expression of Bv8 mRNA. VEGF is known to play an important role in angiogenesis in inflamed synovia. The similar behavior of both factors in arthritis suggests the possible involvement of Bv8 as well as VEGF in angiogenesis in inflamed synovia. In this study, the rate of increase in Bv8 was higher than that in VEGF in arthritis. In normal joints, Bv8 is expressed very weakly, but VEGF expression is higher, which may explain the higher rate of increase in Bv8. In addition to being involved in angiogenesis, Bv8 has diverse functions, including circadian rhythm regulation[11]. Patients with rheumatoid arthritis exhibit an abnormal circadian rhythm[12], which has also been reported in a rat model of arthritis $[13,14]$. Therefore, Bv8 may be involved in arthritis pathogenesis. Ferrara et al. reported Bv8-expressing CD11b+/Gr1+ cells [6.15]. On the other hand, these cells have been shown to be increased in arthritic joints and peripheral tissue in arthritis models $[9,10]$. These observations strongly suggested that the Bv8-positive cells in the present study corresponded to $\mathrm{CD} 11 \mathrm{~b}+/ \mathrm{Gr} 1+$ cells. Therefore, we attempted to clarify this point, and found that the Bv8positve cells in the synovium were positively immunostained with anti-Gr1 antibody; however, we could not detect the presence of $\mathrm{CD} 11 \mathrm{~b}$ in them. Since the tissue sections under study contained osseous and cartilaginous tissue requiring prolonged decalcification, it was necessary to prevent antigen denaturation by employing a fixation procedure. Only anti-CD $11 \mathrm{~b}$ antibody for frozen sections was available, which may have affected the analysis of CD11b expression. This point requires further study.

G-CSF has been reported to increase Bv8 expression in bone marrow $\mathrm{CD} 11 \mathrm{~b}+/ \mathrm{Gr} 1+$ cells, and to be important when Bv8-positive cells are mobilized to tumor tissue [6.16]. G-CSF is closely involved in the pathogenesis of arthritis as well[17]. Therefore, bone marrow CD11b+/ Gr1+ cells may be mobilized to arthritic synovial tissue. On the other hand, some Bv8-positive cells were noted in 
normal synovial tissue. Further studies are necessary to determine what percentage of the Bv8-positive cells that were increased in arthritic synovial tissue were derived from the bone marrow.

\section{Conclusion}

In this study, we demonstrated increased Bv8 expression in the synovium and bone marrow of CIA mice. Further studies are needed to clarify how theses changes are involved in the pathogenesis of arthritis.

\section{Competing interests}

The authors declare that they have no competing interests.

\section{Authors' contributions}

DK and KN designed the study and drafted the manuscript, KN and KF performed the experimental work and the statistical analysis. KY, TU, ET, MY, IK, SS and AY participated in study design and approved the final manuscript.

\section{Acknowledgements}

This study was supported by The Jikei University Research Fund.

\section{References}

I. Mollay C, Wechselberger C, Mignogna G, Negri L, Melchiorri P, Barra D, Kreil G: Bv8, a small protein from frog skin and its homologue from snake venom induce hyperalgesia in rats. Eur J Pharmacol 1999, 374:189-196.

2. Wechselberger C, Puglisi R, Engel E, Lepperdinger G, Boitani C, Kreil G: The mammalian homologues of frog Bv8 are mainly expressed in spermatocytes. FEBS Lett 1999, 462:177-I8I.

3. Ferrara N, LeCouter J, Lin R, Peale F: EG-VEGF and Bv8: a novel family of tissue-restricted angiogenic factors. Biochim Biophys Acta 2004, 1654:69-78.

4. LeCouter J, Lin R, Tejada M, Frantz G, Peale F, Hillan KJ, Ferrara N: The endocrine-gland-derived VEGF homologue Bv8 promotes angiogenesis in the testis: Localization of Bv8 receptors to endothelial cells. Proc Natl Acad Sci USA 2003, 1 00:2685-2690.

5. Negri L, Lattanzi R, Giannini E, Melchiorri P: Bv8/Prokineticin proteins and their receptors. Life Sci 2007, 8 I: I I03-III6.

6. Shojaei F, Wu X, Zhong C, Yu L, Liang XH, Yao J, Blanchard D, Bais C, Peale FV, van Bruggen N, Ho C, Ross J, Tan M, Carano RA, Meng YG, Ferrara N: Bv8 regulates myeloid-cell-dependent tumour angiogenesis. Nature 2007, 450:825-83I.

7. Kurosaka D, Yasuda J, Yoshida K, Yasuda C, Toyokawa Y, Yokoyama T, Kingetsu I, Yamada A: Kinetics of circulating endothelial progenitor cells in mice with type II collagen arthritis. Blood Cells Mol Dis 2005, 35:236-240.

8. Kurosaka D, Yoshida K, Yasuda J, Yasuda C, Noda K, Furuya K, Ukichi T, Kingetsu I, Joh K, Yamaguchi N, Saito S, Yamada A: The effect of endostatin evaluated in an experimental animal model of collagen-induced arthritis. Scand I Rheumatol 2007, 36:434-44 I.

9. Wong PK, Egan PJ, Croker BA, O'Donnell K, Sims NA, Drake S, Kiu H, McManus EJ, Alexander WS, Roberts AW, Wicks IP: SOCS-3 negatively regulates innate and adaptive immune mechanisms in acute IL-I-dependent inflammatory arthritis. J Clin Invest 2006, I | 6: I57|-I58I.

10. Yim YK, Lee H, Hong KE, Kim YI, Lee BR, Son CG, Kim JE: Electroacupuncture at acupoint $\mathrm{ST} 36$ reduces inflammation and regulates immune activity in Collagen-Induced Arthritic Mice. Evid Based Complement Alternat Med 2007, 4:5I-57.

I I. Cheng MY, Bullock CM, Li C, Lee AG, Bermak JC, Belluzzi J, Weaver DR, Leslie FM, Zhou OY: Prokineticin 2 transmits the behavioural circadian rhythm of the suprachiasmatic nucleus. Nature 2002, 4 I 7:405-4I0.
12. Cutolo M, Straub RH: Circadian rhythms in arthritis: hormonal effects on the immune/inflammatory reaction. Autoimmun Rev 2008, 7:223-228.

13. Seres J, Herichová I, Roman O, Bornstein S, Jurcovicová J: Evidence for daily rhythms of the expression of proopiomelanocortin, interleukin-I-beta and interleukin-6 in adenopituitaries of male long-evans rats: effect of adjuvant arthritis. Neuroimmunomodulation 2004, I I:3 | 6-322

14. Esquifino $\mathrm{Al}$, Cano $\mathrm{P}$, Jiménez-Ortega $\mathrm{V}$, Fernández-Mateos $\mathrm{P}, \mathrm{Cardi}$ nali DP: Neuroendocrine-immune correlates of circadian physiology: studies in experimental models of arthritis, ethanol feeding, aging, social isolation, and calorie restriction. Endocrine 2007, 32:1-19.

I5. Shojaei F, Wu X, Malik AK, Zhong C, Baldwin ME, Schanz S, Fuh G, Gerber HP, Ferrara N: Tumor refractoriness to anti-VEGF treatment is mediated by CDI Ib+GrI+ myeloid cells. Nat Biotechnol 2007, 25:91 I-920.

16. Shojaei F, Ferrara N: Refractoriness to antivascular endothelial growth factor treatment: role of myeloid cells. Cancer Res 2008, 68:550I-5504.

I7. Lawlor KE, Campbell IK, Metcalf D, O'Donnell K, van Nieuwenhuijze A, Roberts AW, Wicks IP: Critical role for granulocyte colonystimulating factor in inflammatory arthritis. Proc Natl Acad Sci USA 2004, I01: I 1398-1 | 403.

\section{Pre-publication history}

The pre-publication history for this paper can be accessed here:

http://www.biomedcentral.com/1471-2474/10/45/pre pub
Publish with Bio Med Central and every scientist can read your work free of charge

"BioMed Central will be the most significant development for disseminating the results of biomedical research in our lifetime. "

Sir Paul Nurse, Cancer Research UK

Your research papers will be:

- available free of charge to the entire biomedical community

- peer reviewed and published immediately upon acceptance

- cited in PubMed and archived on PubMed Central

- yours - you keep the copyright
BioMedcentral 